\section{Commentary: Less is more}

\author{
Stephanie H. Chang, MD
}

The influence of high-volume centers and surgeons on patient outcomes for complex procedures has been studied, ${ }^{1}$ but is hard to fully quantify. Ely and colleagues ${ }^{2}$ evaluate the long-term effect of regionalization for lung cancer resection in an integrated health care system, showing improved 1-year and 3-year survival with regionalization. The number of hospitals performing pulmonary resection went from 21 before regionalization to 5 after regionalization, with average facility volume increasing from 17 to 43 resections per year. Regarding long-term survival, regionalization was associated with a $43 \%$ relative reduction in mortality risk.

Among the most interesting findings from this article is that the survival benefit seen after regionalization increased with time, with the Kaplan-Meier survival curves becoming parallel after 4 years. At 1 year, there was a $5.4 \%$ absolute difference in mortality $(11.1 \%$ pre and $5.7 \%$ post), whereas at 3 years, there was an $8.5 \%$ difference $(25.5 \%$ vs $17.0 \%)$. The increased difference highlights the potential need to assess surgeons and facilities on their long-term outcomes after pulmonary resection because 30- and 90-day mortality does not accurately reflect differences in survival. This increased difference in survival after regionalization may also be attributed to the multidisciplinary care that lung cancer patients require. As the authors discuss, a multidisciplinary tumor board with thoracic surgeon attendance was also instituted after regionalization. Thus, potentially improved neoadjuvant and adjuvant care, as well as better surveillance, may also play a role in the improving long-term survival.

\footnotetext{
From the Division of Thoracic Surgery, Department of Cardiothoracic Surgery, New York University Langone Health, New York, NY.

Disclosures: The author reported no conflicts of interest.

The Journal policy requires editors and reviewers to disclose conflicts of interest and to decline handling or reviewing manuscripts for which they may have a conflict of interest. The editors and reviewers of this article have no conflicts of interest.

Received for publication March 26, 2021; revisions received March 26, 2021; accepted for publication March 29, 2021; available ahead of print April 2, 2021.

Address for reprints: Stephanie H. Chang, MD, Division of Thoracic Surgery, Department of Cardiothoracic Surgery, New York University Langone Health, 530 First Ave, Suite 9V, New York, NY 10016 (E-mail: stephanie.chang@nyulangone.org). J Thorac Cardiovasc Surg 2022;163:778

$0022-5223 / \$ 36.00$

Copyright (c) 2021 by The American Association for Thoracic Surgery

https://doi.org/10.1016/j.jtcvs.2021.03.096
}

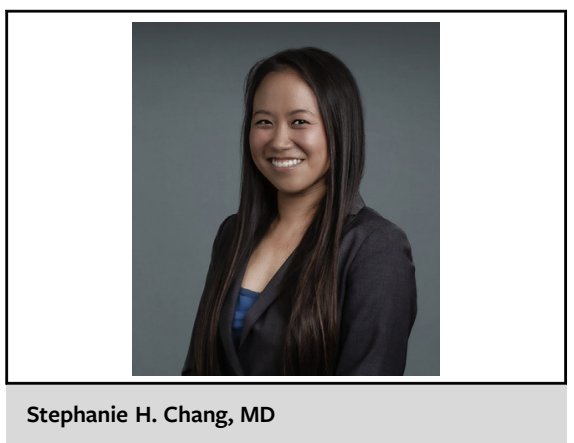

CENTRAL MESSAGE

The improved long-term survival with lung cancer resection after regionalization highlights the need for long-term metrics and the improved care at higher volume centers.

Regionalization leads to a fewer facilities with higher volume, and thus more experience caring for complex patients. Because the experience described here was performed in 1 large, integrated system, it will be difficult to institute across the nation, but this article emphasizes the importance of specialized care. Hospitals that perform few anatomic thoracic resections a year should refer their patients to larger centers that have expertise, due to experienced surgeons, streamlined perioperative care, and associated cancer centers ${ }^{3}$ to provide the best patient care possible.

\section{References}

1. Birkmeyer JD, Siewers AE, Finlayson EV, Stukel TA, Lucas FL, Batista I, et al. Hospital volume and surgical mortality in the United States. $N$ Engl J Med. 2002;346:1128-37.

2. Ely S, Jiang S-F, Dominguez DA, Patel AR, Ashiku SK, Velotta JB. Effect of thoracic surgery regionalization on long-term survival after lung cancer resection. J Thorac Cardiovasc Surg. 2022;163:769-77.

3. Fong ZV, Chang DC, Hur C, Jin G, Tramontano A, Sell NM, et al. Variation in long-term oncologic by type of cancer center accreditation: an analysis of SEER-Medicare population with pancreatic cancer. Am J Surg. 2020;220:29-34. 